\title{
SOME PROBLEMS ENCOUNTERED IN ADMINISTERING HEAD START
}

\author{
By Sharon Brooks, BA, ${ }^{*}$ and Robert A. Bagramian, DDS, Dr. $\mathrm{PH}^{* *}$
}

Mrs. Brooks, a Junior Dental Student, recites, in a homespun way, her reaction to one Summer Head Start Program.

The local, federally-funded Project Head Start is designed primarily to prepare the pre-school children of Washtenaw County's low-income families to enter kindergarten. In addition to instruction in the verbal, cognitive, and social skills that the children need to become successful in school, the program provides a nourishing hot lunch, complete dental and medical examinations, and the necessary supervision that has to follow. The report, about to be presented, will discuss the administrative problems encountered in supervising the program.

The program had quarters in five different centers of the County but the main center was located in the City of Ann Arbor. Training of the staff began June 21, 1971 for carrying out the program during the period of June 30 to August 18 while the young children to be treated were in school. A program spread throughout a large county encountered initial problems in logistics, particularly in communicating. The short duration of the program also created difficulties in follow-up. It seems appropriate, in retrospect, to discuss eight facets of the programming, one of which includes the recommendations gained from the experience with this activity.

\section{Initiatory Planning}

Ideally such a health program should be planned well in advance of the actual arrival of the children. Dentists and physicians then can be oriented for their participation, appointments for dental treatment can be made, a program for the topical application of fluoride can be arranged, and medical supplies and literature for health education can be ordered. To accomplish the planning comfortably, the health coordinator must be a person in the community who is willing to work a few months in advance of the rest of the staff.

For the Summer Head Start Program, the director is hired in the spring and then hires the rest of his staff, none of whom begin their activity until the first day of training, approximately one week before the children arrive. The current director had served previously for three summers, and was able, therefore, to supply continuity for the various phases of the program in 1971. Inasmuch as he recently accepted a position as teacher in another state, he may not be able to participate in the important early planning for next year.

For 1971 , the health team consisted of two junior dental students supported by the apprenticeship grants of the U. S. Public Health Service and one second-year medical student hired by Head Start. The dental students, one of whom was with Head Start in 1970 , began the planning on June 1 and were joined shortly by the medical student. Since he was not scheduled to begin until June 21 , for 20 days he served as a volunteer.

The health team was able to arrange most aspects of the program satisfactorily in the

\footnotetext{
* Mrs. Brooks, a junior dental student and summer public health apprentice at the University of Michigan, School of Dentistry, Ann Arbor, Mich. 48104, served actively in the 1971 Summer Head Start Program for Washtenaw County.

**Dr. Bagramian is Chairman of the Department of Community Dentistry at the School of Dentistry, and he served as an advisor to the same program.
} 
short time available. One exception was the planning for the topical application of fluoride which has to be completed in mid-winter. One of the dental students is expected to act as the liaison agent during the winter to ensure that a fluoride program will function in 1972 Head Start.

\section{Health Histories and Permission-Slips}

Each parent must fill out a two-page application to enroll a child in the Head Start Program. Approximately two weeks before the program begins, letters for acceptance are mailed. Then the process of collecting health histories and permission-slips begins. In previous years the teachers and teacher-aides made home visits before the children arrived, in order to meet the parents, discuss the program, and obtain the health histories and the permission-slips. In 1971 the director discontinued this visiting because of a preference for an extra two days of training for the staff.

All of the required forms, including the two-page health history, immunization record, dental permission-slip, and general permission-slip, were mailed out with the letter for acceptance of the program. Stamped, addressed envelopes were provided for the return of the forms. The response was poor. All of the parents, who had telephones and had not returned the forms within one week, were called. As soon as the staff assembled, the family coordinators were asked to contact the remaining families. By the first day of the children's class one-half of the required forms had been received.

The laboratory-examination, scheduled for the second week of class, was the most seriously affected by the slow return of permission-slips. The testing is performed early in the program because the physicians require considerable information before the physical examination of the children late in summer. Measurements of height and weight expressed in percentiles, urinalysis, tests for hemoglobin and sickle cell anemia, and the TB tine tests, all are needed. A number of children had to be omitted or rescheduled because their parents had not returned the forms.

\section{Attendance}

Attendance was a severe problem in the 1971 Summer Head Start, particularly in the two large centers of Ann Arbor and Ypsilanti. Ann Arbor was scheduled to treat 94 children. Daily attendance, however, ranged between 50 and 75. Part of the problem was created by bus-drivers who failed to pick up the children. Part of the problem was caused by the failure of some of the parents to get the children ready for school. Many children actually were recruited for the program by a community worker. The parents often did not know the scope of the program or what was expected of them. They, hence, were apathetic. Children were dropped and added as late as the fifth week of an eight-week program. These late additions missed much of the initial health screening, although most of them received physical examinations. Several make-up sessions were scheduled for each part of the health program, but some children also were absent from all of them.

\section{Communication}

Communication generally was good during the Program, despite the inclusion of children from a large populous county. Some problems arose, however, when instant communication with the outlying centers was needed. Sometimes nobody was in the center to answer the telephone. At times letters had to be sent home with the children and this type of communication entailed a 22-to-36-mile round-trip drive to deliver them. In one center occasional problems with dental appointments occurred which easily could have been solved if the person in charge had called some member of the health team.

\section{Follow-up}

As has been stated, the Summer Head Start Program lasts eight weeks, although the 
money for the Program continues available until the end of the year. Dental follow-up was begun in the second week of the program and by the end of August all of the children experiencing carious lesions were seen at least once and many had treatment completed. Parents are responsible for taking their children to the dentist after the formal Program is completed.

Few medical referrals were made, but some of the cardiac and psychomotor testing is not completed before the end of the program. Follow-up then will have to be assigned to the already overworked school and public health nurses because the staff of Head Start finishes on August 20. The physician who examined the children will be arranging for follow-up at University Hospital and may make certain that it is accomplished himself.

\section{Professional Cooperation}

Cooperation from professional people in the community generally was very good. A nurse recruited a number of other nurses and non-professional people to assist with the laboratory examinations. A pediatric resident and a medical technologist volunteered their time. The Washtenaw County Health Department donated vaccines, syringes, and a nurse to help with immunization. Several local dentists set aside time to treat the children.

Some dentists in some communities were wary about treating the children of Head Start because of so many broken appointments in the past. For that reason the staff undertook the responsibility of taking the children to the dentist instead of relying on the parents. Some dentists also seemed to be reluctant to participate because they would be paid through the Delta Dental Plan of Michigan which assumed this portion of administration.

\section{Budget}

At the beginning of the summer nobody knew positively whether the budget would be adequate to treat all dental and medical needs. Treatment was arranged first for children with medical referrals and those with obvious carious lesions. As money was confirmed as available, the children with no obvious lesions then can be seen by a dentist for a thorough examination and a prophylaxis. The parents of these children are responsible for making appointments and taking their children to the dentist. One may expect that probably less than half will do so if the parents react as in 1970. For this reason money may be left which could have been used earlier in the summer.

\section{Some Recommendations}

The health forms and permission-slips should be so arranged and simplified that a minimum number are required. Someone trained in law should rewrite the permissionslips so that they will be acceptable to all concerned - Head Start, the County Department of Health, and the school system.

Once the proper forms are designed, they should be incorporated with the application that the mother fills out to enroll her child. Children should not be admitted to class without the forms. In addition to improvement of the health program, this plan would eliminate early those families not sincerely interested in the Program and lessen absenteeism.

The health coordinator should be hired in the early spring parttime and allowed to start planning the health program in advance. Local physicians, hospital residents, health departments, and the dental society should be contacted promptly by this person.

To aid communication, the health coordinator should attend weekly staff meetings with the teachers and their aides. Written instructions concerning dental appointments and transportation should be given to the person responsible and to at least one other person in each center. 
The budget should be defined promptly and clearly so that maximum utilization of funds can occur in the summer when the staff is available for follow-up.

All of the children with visible carious lesions were taken to a dentist by the staff of Head Start and many had treatment completed by the end of the summer. Approximately 50 percent, however, had no visible dental lesions. Many of these children have never visited a dentist before and should have an opportunity to visit him during Head Start. These children, however, are low in priority for treatment, hence, their parents must be responsible for taking them to the dentist. Many of the parents will not accept such responsibility.

To ensure that each child has a thorough examination and prophylaxis, at a reasonable cost to the program, it has been suggested that the School of Dentistry at the University of Michigan be contacted concerning treatment for these children. There will be a class of senior students in the clinic full-time during the summer, beginning in 1972 . Each student would have to examine but two of these children in order to prepare for, and deliver treatment to all of the Head Start children. Oral problems requiring extensive treatment could be referred to private practitioners if the School desired. In this way, no child would miss the opportunity of visiting a dentist because his parents did not accept responsibility.

\section{A Student Evaluates}

Students view the general practitioner of dentistry as an isolationist. He is isolated from his profession, from education, and from the society in which he lives. He views his practice as settling down where money is made and social consciousness is at a minimum. The practitioner then sits back and relieves himself of responsibility by permitting "the powers that be" to dictate the policies of his profession. (Harry H. Martin, President, American Student Dental Association, in the Bulletin of the American Association of Dental Editors for Winter, 1972)

\section{The Auditory Oral Cavity}

Men are about to hear through their mouths rather than their ears. Two scientists in California suggest that men will be able to hear through their teeth. A tiny receiver no bigger than a tooth can be located in the space left by a missing tooth. After a period of practice with this auditory equipment, a patient can apologize, "I couldn't hear you dear, my mouth was closed." (David Hendin in the Ann Arbor News for March 16, 1972)

\section{Today's Family}

The family of today still possesses the greatest opportunity available to act significantly. It can ensure the continuance of all that makes people human - those virtues called love, justice, freedom, prudence, and courage. Everyone in a dynamic family has something and someone to think about besides himself. (From Royal Bank of Canada Monthly Letter for February, 1972) 